\title{
Autoregulation of cochlear blood flow in young and aged mice
}

Received: 29 April 1994 / Accepted: 23 November 1994

\begin{abstract}
Autoregulation is the capacity of an organ system to maintain organ blood flow constant in response to changes in arterial blood pressure (BP). The current study was carried out to investigate the effect of age on autoregulation of cochlear blood flow (CBF) in mice. CBF was measured using a laser-Doppler flowmeter while BP was increased by angiotensin II injections and decreased by exsanguination in 2-month-old, 10-month-old and 18month-old CBA mice. Autoregulation of CBF was significantly weaker in the 2-month-old mice when compared to the older mice. Although CBF autoregulation was weaker in the 18-month-old mice compared to the 10month-old mice, this difference was not statistically significant. These results suggest that autoregulation changes with maturation and age. Findings are discussed in relationship to the possible development of presbycusis.
\end{abstract}

Key words Cochlear blood flow $\cdot$ Autoregulation . Angiotensin $\cdot$ Blood pressure $\cdot$ Presbycusis

\section{Introduction}

Human temporal bone studies and various experimental models have demonstrated age-related morphometric capillary changes which have been correlated with hearing loss [9, 23]. Prazma et al. [17] reported that cochlear blood flow (CBF) in old gerbils was less than that in young animals and used these findings to support a vascular theory of presbycusis. However, other studies have shown that there is no significant difference in the cochlear vasculature between young and old guinea pigs [1],

T. Nakashima · J. M. Miller · A. L. Nuttall

Kresge Hearing Research Institute, The University of Michigan. Ann Arbor, Michigan, USA

T. Nakashima ( $\mathrm{W})$

Department of Otorhinolaryngology,

Nagoya University School of Medicine,

65, Tsurumai-cho, Showa-ku, Nagoya 466, Japan and that CBF does not vary between young and aged normotensive rats [8]. These conflicting results may reflect a difference in the species studied or the ages at which animals were selected for investigations.

Another approach to study age-related changes in blood circulation in an organ is to determine the capability of the system to control blood flow. Local autoregulation of blood flow is an important regulatory mechanism of the cochlea $[2,20]$. One function of autoregulation is to keep CBF constant in the face of changes in arterial blood pressure (BP). As such, it is an intrinsic and dynamic activity of vascular smooth muscle in the cochlea. Vascular reactivity is a natural ability of most organs and, given the types of changes that occur in vessels with aging [6], one can hypothesize that this autoregulatory property of $\mathrm{CBF}$ varies with age.

Previous studies have shown that the mouse is a suitable animal for age-related studies because of its short life span and its previous use in investigations of age-related hearing loss [7, 14]. Mice have also exhibited a form of pathology similar to that observed in man. Moreover, studies have characterized morphological changes of the cochlea in CBA mice at various ages [13]. In the present experiment, we have examined the effect of age on autoregulation of $\mathrm{CBF}$ and inner ear pathology in $\mathrm{CBA}$ mice.

\section{Materials and methods}

Twelve male CBA mice were separated into three equal groups according to age: 2 months old, 10 months old and 18 months old. Animals were anesthetized with subcutaneous ketamine $(100 \mathrm{mg} /$ $\mathrm{kg})$ and xylazine $(10 \mathrm{mg} / \mathrm{kg})$. This was supplemented by subcutaneous injections of $50 \mathrm{mg} / \mathrm{kg}$ ketamine at 30 -min intervals. Core body temperature was measured with a rectal probe and was maintained at $37 \pm 1^{\circ} \mathrm{C}$ by a thermoregulated heating blanket.

$\mathrm{BP}$ was measured through a PE10 cannula inserted into the femoral artery. The right tympanic bulla was opened and the middle ear mucosa over the lateral wall of the cochlea was removed. Using a laser-Doppler flowmeter (TSI Laser Flo), CBF was measured after placing a 0.8 -mm-diameter laser-Doppler probe over the lateral wall of the cochlea.

After observing a stable level of CBF for $3 \mathrm{~min}$. autoregulation was estimated by measuring CBF changes caused by increasing and decreasing systemic BP. To increase BP, $1 \mu \mathrm{g} / \mathrm{kg}$ angiotensin II (Sigma) was dissolved in $0.02 \mathrm{ml}$ of $0.15 \mathrm{M} \mathrm{NaCl}$, and was ad- 
ministered by a single bolus injection through the femoral artery cannula. This resulted in a significant transient increase in BP, returning to baseline level in 2.5-3.5 min. After baseline BP and CBF were re-established, a second dose of angiotensin II $(5 \mu \mathrm{g} / \mathrm{kg}$ in $0.02 \mathrm{ml} 0.15 \mathrm{M} \mathrm{NaCl}$ ) was administered by a single bolus injection. Recovery of BP and CBF was again allowed to occur, returning to baseline levels in 3.5-5.0 min. Angiotensin II applications were followed by stepwise hypotension induced by a 10 -min withdrawal of about $0.5 \mathrm{ml}$ blood from the cannula inserted into the femoral artery. In one 2-month-old mouse and one 18-month-old mouse, withdrawal of blood was performed without prior administration of angiotensin II.

The relationship between $\mathrm{BP}$ and $\mathrm{CBF}$ was plotted for every 5 $\mathrm{mmHg}$ change of $\mathrm{BP}$, or every $5 \mathrm{~min}$ in the case that BP $\mathrm{d}_{1} \mathrm{~d}$ not show a 5- mmHg change during the 5-mun measurement period.

\section{Results}

Initial mean $\mathrm{BP}$ was $77.9 \pm 11.7 \mathrm{mmHg}, 81.8 \pm 9.2 \mathrm{mmHg}$ and $72.5 \pm 8.3 \mathrm{mmHg}$ in the 2-month-old, 10-month-old

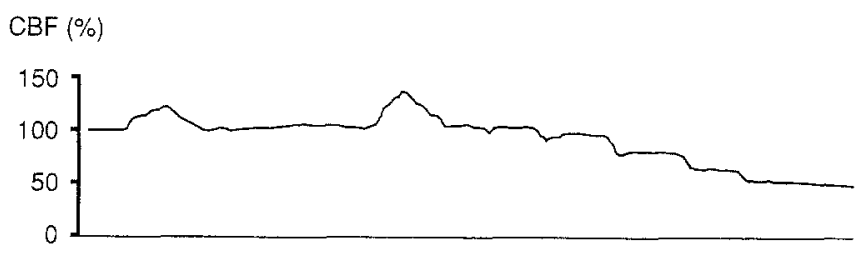

$\mathrm{BP}(\mathrm{mmHg})$

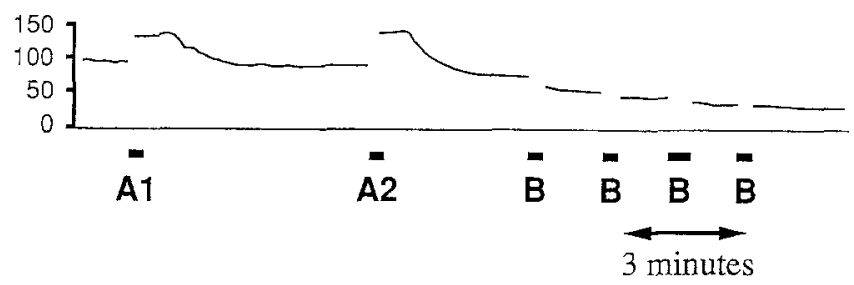

Fig. 1 Changes in cochlear blood flow (CBF) and blood pressure (BP) following angiotensin II injection and exsanguination. BP could not be measured durng the injections and blood withdrawal because BP was measured through the same cannula. (Al $1 \mu \mathrm{g} / \mathrm{kg}$ angiotensin II injection, $A 25 \mu \mathrm{g} / \mathrm{kg}$ angiotensin II injection, $B$ blood withdrawal)

Table 1 Maximum elevation (\%) in blood pressure $(B P)$ and cochlear blood flow $(C B F)$ following $1 \mu \mathrm{g} / \mathrm{kg}$ and $5 \mu \mathrm{g} / \mathrm{kg}$ angiotensin II injections

\begin{tabular}{|c|c|c|c|c|c|}
\hline \multirow{2}{*}{$\begin{array}{l}\text { Animal } \\
\text { no. }\end{array}$} & \multirow{2}{*}{$\begin{array}{l}\text { Age } \\
\text { (months) }\end{array}$} & \multicolumn{2}{|c|}{$1 \mu \mathrm{g} / \mathrm{kg}$ angiotensin II } & \multicolumn{2}{|c|}{$5 \mu \mathrm{g} / \mathrm{kg}$ angiotensin $\mathrm{I}$} \\
\hline & & BP & $\mathrm{CBF}$ & $\mathrm{BP}$ & $\mathrm{CBF}$ \\
\hline 1 & 2 & 53 & 52 & 124 & 47 \\
\hline 2 & 2 & 58 & 60 & 59 & 41 \\
\hline 3 & 2 & 80 & 54 & 90 & 62 \\
\hline 4 & 10 & 54 & 14 & 77 & 28 \\
\hline 5 & 10 & 57 & 19 & 98 & 24 \\
\hline 6 & 10 & 46 & 35 & 62 & 38 \\
\hline 7 & 10 & 40 & 26 & 60 & 32 \\
\hline 8 & 18 & 68 & 16 & 127 & 50 \\
\hline 9 & 18 & 36 & 27 & 129 & 38 \\
\hline 10 & 18 & 67 & 14 & 80 & 14 \\
\hline
\end{tabular}

and 18-month-old mice, respectively. These values were not significantly different among the three age groups. Figure 1 shows an example of $\mathrm{BP}$ and $\mathrm{CBF}$ changes that were caused by the two injections of angiotensin II and subsequent exsanguination. Following angiotensin II injection, both $\mathrm{BP}$ and $\mathrm{CBF}$ rose transiently but $\mathrm{CBF}$ returned to its baseline level faster than BP.

The maximum elevations in $\mathrm{BP}$ and $\mathrm{CBF}$ caused by angiotensin II injections in each animal are shown in Table 1. In all animals, the BP elevation was greater after the $5 \mu \mathrm{g} / \mathrm{kg}$ injection than after the $1 \mu \mathrm{g} / \mathrm{kg}$ injection, while elevations in CBF for the $1 \mu \mathrm{g} / \mathrm{kg}$ and $5 \mu \mathrm{g} / \mathrm{kg}$ injections were similar (Fig.2). The elevation of BP was $55.9 \pm 13.4 \%$ and $90.6 \pm 27.9 \%$ following the $1 \mu \mathrm{g} / \mathrm{kg}$ and the $5 \mu \mathrm{g} / \mathrm{kg}$ angiotensin II injections, respectively. In contrast, the elevation of $\mathrm{CBF}$ was $31.7 \pm 17.7 \%$ and $37.4 \pm$ $13.8 \%$ following the $1 \mu \mathrm{g} / \mathrm{kg}$ and the $5 \mu \mathrm{g} / \mathrm{kg}$ angiotensin II injections, respectively.

The elevations in BP were not significantly different among the three age groups but the degree of elevation in $\mathrm{CBF}$ in the 2-month-old mice was larger than in the other two age groups. When $1 \mu \mathrm{g} / \mathrm{kg}$ angiotensin II was injected, the differences in the degree of elevation in $\mathrm{CBF}$ between the 2-month-old mice and the other two age groups were statistically significant (ANOVA test, $P<0.01$ ). When $5 \mu \mathrm{g} / \mathrm{kg}$ angiotensin II was injected, the difference in the degree of elevation in CBF between the 2-month-old mice and 10-month-old mice still existed, although the difference was not statistically significant.

Figures 3-5 show the relationships between $\mathrm{BP}$ and $\mathrm{CBF}$ in the 2-month-old, 10-month-old and 18-month-old mice, respectively. Autoregulation of $\mathrm{CBF}$ varied among the three groups. Regulation was greatest in the10-monthold group, less so in the 18-month-old group, and least in the 2-month-old group. In order to statistically evaluate the autoregulation of CBF, a least-squares fit of a cubic regression curve was determined for the data from each animal, as shown in Fig. 6. This represented the minimum equation order that would describe the typical autoregulatory function of a whole organ system.

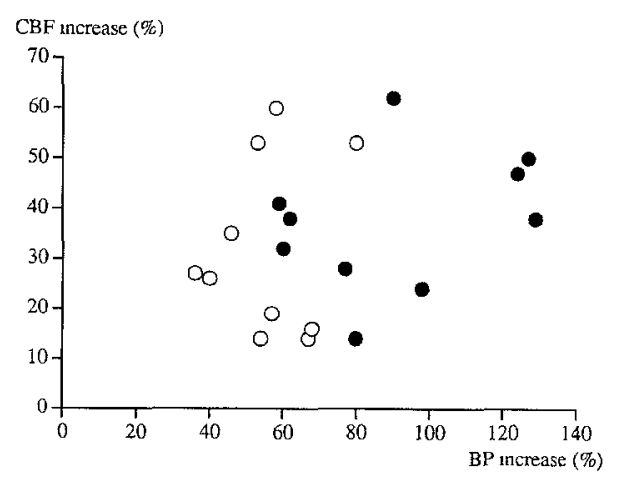

Fig. 2 Relationship between the maxımum elevation of BP and CBF following each injection of angiotensin II. Open curcles indicate $1 \mu \mathrm{g} / \mathrm{kg}$ angiotensin $\mathrm{I}$ injections and closed circles indicate $5 \mu \mathrm{g} / \mathrm{kg}$ angiotensin II injections 


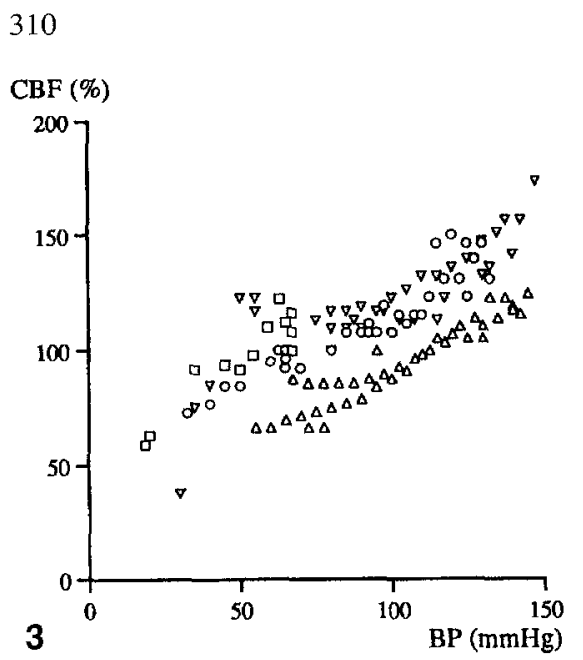

Fig. 3 Relationship between BP and CBF in 2-month-old mice. Different symbols represent individual animals

Fig. 4 Relationship between BP and CBF in 10-month-old mice. Different symbols represent individual animals

Fig. 5 Relationship between BP and CBF in 18-month-old mice. Different symbols represent individual animals

The autoregulated range was defined as that change in BP over which CBF was maintained between $90 \%$ and $110 \%$ of its resting level. The autoregulation range for the 2-month-old group was $40.5 \pm 14.4 \mathrm{mmHg}, 79.3 \pm 16.7$ $\mathrm{mmHg}$ in the 10-month-old group and $61.7 \pm 13.7 \mathrm{mmHg}$ in the 18-month-old group. The BP range of the 2-monthold mice was significantly smaller than that in the 10 month old mice $(P<0.01)$. The differences in the autoregulated range between the 2 -month-old and 18 -monthold mice, and between the 10-month-old and 18-monthold mice, were not significant statistically $(P>0.05)$.

\section{Discussion}

Autoregulation of CBF has been investigated using angiotensin II in rats [18] and guinea pigs [11]. Quirk et al. [18] suggested that CBF was autoregulated in Wister-Kyoto rats by showing that angiotensin II produced an initial increase in CBF followed by a slow steady return to baseline despite sustained elevation in systemic BP. Kawakami et al. [11] reported that CBF had some autoregulation, but was less than brain blood flow in adult guinea pigs.

To our knowledge, there have been no reports about the effect of age on autoregulation of CBF. At present, the mouse is a good model for such studies because it has certain genetically determined and age-related physiological changes. Our present study has demonstrated the feasibility of using the mouse to study the mechanisms and pathology of $\mathrm{CBF}$, and was able to demonstrate a change in CBF autoregulation with maturation and age, although initial BP was not significantly different among three age groups as previously reported in young and aged CBA mice [21].

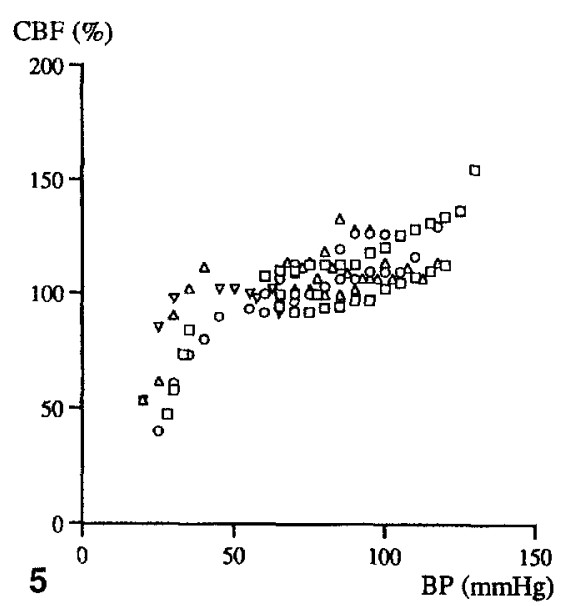

Fig. 6 An example of a cubic regression curve and "autoregulated area" in one animal shown by squares in Fig. 5. Mean BP was increased twice by $1 \mu \mathrm{g} / \mathrm{kg}$ angiotensin II and $5 \mu \mathrm{g} / \mathrm{kg}$ angiotensin II (between 60 and $140 \mathrm{mmHg}$ ) and lowered by exsanguination (between 20 and $40 \mathrm{mmHg}$ )

Regarding age-related changes in autoregulation, it has been shown that autoregulation of brain blood flow is reduced in neonates or infants $[10,19]$, as well as in aged subjects $[4,24]$. It has also been thought that impaired autoregulation of blood flow in the brain or vestibule may play a role in inducing vertigo in elderly patients with orthostatic hypotension [16]. In past studies, CBF has been considered similar to brain blood flow [12, 15] and has been included as part of the cerebral circulation. Recent studies in the guinea pig, however, have shown strong intrinsic (local) autoregulation in the cochlea $[2,20]$. If autoregulation plays a major role in maintaining CBF, a reduction in autoregulation of the cochlea may account for inner ear pathology occurring with age, inclusive of presbycusis. In our study, there was a trend toward lessened autoregulation of CBF in 18month old mice compared to that observed in 10-monthold mice, although the difference was not statistically significant. 
$\mathrm{Li}$ and Borg [14] reported that ABR thresholds rose gradually from 6 to 18 months of age and rose rapidly after 18 months of age in CBA mice. Our findings suggest that a disturbance of autoregulation in CBF is perhaps only one of a number of conditions that lead to sensitivity changes with presbycusis.

Shone et al. [22] reported that 21-month old CBA mice were more susceptible to noise injury than 6-month-old mice. Our data indicate that autoregulation of CBF in mice older than 21 months may be significantly impaired compared to 10-month-old animals and may be a factor in noise-induced loss. Moreover, impairment of CBF might be related to temporary noise-induced threshold shifts in older subjects who develop arteriosclerosis of cochlear blood vessels $[3,5]$. In future studies, it is our intent to examine temporary and permanent noise-induced threshold shifts in relation to CBF and age-dependent changes in vascular reactivity.

Acknowledgements We are grateful to Nadine Brown and Gary Dootz for their technical assistance in performing these experiments. We also wish to thank Professor Noriyuki Yanagita, Nagoya University School of Medicine, for his support of this study. This work was supported by United States NIH research grants DC 00105 and AG 08885.

\section{References}

1. Axelsson A (1971) The cochlear blood vessels in guinea pigs of different ages. Acta Otolaryngol (Stockh) 72:172-181

2. Brown IN, Nuttall AL (1994) Autoregulation of cochlear blood flow in the guinea pig. Am J Physiol 266:458-467

3. Dengerink H. Miller J, Axelsson A, Vertes D, Dalfsen PV (1985) The recovery of vascular changes following brief noise exposure. Acta Otolaryngol (Stockh) 100:19-25

4. Fujishima M, Sadoshima S. Ogata J, Yoshida F, Shiokawa O, Ibayashi S, Omae T (1984) Autoregulation of cerebral blood flow in young and aged spontaneously hypertensive rats (SHR). Gerontology 30:30-36

5. Hawkins JE Jr (1971) The role of vasoconstruction in noise-induced hearıng loss. Ann Otol Rhinol Laryngol 80:903-913

6. Helfaer MA, Kursch JR, Haun SE, Koehler RC, Traystman RJ (1991) Age-related cerebrovascular reactivity to $\mathrm{CO}_{2}$ after cerebral ischemia in swine. Am J Physiol 260:H1482-488

7. Henry KR, McGinn MD (1992) The mouse as a model for human audition. A review of the literature. Audiology 31:181189
8. H1llerdal M, Borg E, Engstrom B, Hultcrantz E (1987) Cochlear blood flow in relation to age in normotensive and spontaneous hypertensive rats. Acta Otolaryngol (Stockh) 104:243250

9. Johnsson LG, Hawkins JE Jr (1972) Vascular changes in the human inner ear associated with aging. Ann Otol Rhinol Laryngol 81:364-377

10. Jorch G, Jorch N (1987) Failure of autoregulation of cerebral blood flow in neonates studied by pulsed Doppler ultrasound of the internal carotid artery. Eur J Pediatr 146:468-472

11. Kawakami M, Makimoto K, Fukuse S. Takahashi H (1991) Autoregulation of cochlear blood flow. A comparison of cerebral blood flow with muscular blood flow. Eur Arch Otorhinolaryngol 248:471-474

12. Lawrence M, Nuttall AL, Bulgio PA (1977) Oxygen reserve and autoregulation in the cochlea. Acta Otolaryngol (Stockh) $83: 146-152$

13. Li HS (1992) Genetic influences on susceptibility of the aud1tory system to aging and environmental factors. Scand Audiol 21 [Suppl 36]:1-39

14. Li HS, Borg E (1991) Age-related loss of auditory sensitivity in two mouse genotypes. Acta Otolaryngol (Stockh) 111:827--834

15. Miller JM, Marks NJ, Goodwin PC (1983) Laser-Doppler measurements of cochlear blood flow. Hear Res 11:385-394

16. Ohashi N, Yasumura S, Nakagawa H. Shojaku H. Mizukoshi K (1991) Cerebral autoregulation in patients with orthostatic hypotension. Ann Otol Rhinol Laryngol 100:841-844

17. Prazma J, Carrasco VN, Butler B, Waters G, Anderson T, Pillsbury HC (1990) Cochlear microcirculation in young and old gerbils. Arch Otolaryngol Head Neck Surg 116:932-936

18. Quirk WS, Dengerink HA, Coleman JK, Wright JW (1989) Cochlear blood flow autoregulation in W1star-Kyoto rats. Hear Res 41:53-60

19. Ramaekers VT, Casaer P, Daniels H, Marchal G (1990) Upper limits of brain blood flow autoregulation in stable infants of various conceptional age. Early Hum Dev 24:249-258

20. Ren TY, Avinash GB, Nuttall AL, Miller JM, Laurikainen E, Qurrk WS (1994) Dynamic response of cochlear blood flow to occlusion of the anterior inferior cerebellar artery in guinea pıg. J Appl Physiol 76:212-217

21. Schlager G (1966) Systolic blood pressure in eight inbred strains of mice. Nature 212:519-520

22. Shone G, Altschuler RA, Miller JM, Nuttall AL (1991) The effect of noise exposure on the aging ear. Hear Res 56:173-178

23. Tachibana M, Yamamichi I, Nakae Y, Hirasugi Y, Machino M, Mizukoshi $O$ (1984) The site of involvement of hypertension within the cochlea. Acta Otolaryngol (Stockh) 97:257-265

24. Wollner L. McCarthy ST, Soper ND, Macy DJ (1979) Failure of cerebral autoregulation as a cause of brain dysfunction in the elderly. BMJ 28:1117-1118 